University of Nebraska - Lincoln

DigitalCommons@University of Nebraska - Lincoln

Civil Engineering Faculty Publications

Civil Engineering

2011

\title{
Improving Safety and Mobility at High-Speed Intersections with Innovations in Sensor Technology
}

\author{
Anuj Sharma \\ University of Nebraska - Lincoln, anujs@iastate.edu \\ Darcy M. Bullock \\ Purdue University, darcy@purdue.edu \\ Senem Velipasalar \\ University of Nebraska - Lincoln, svelipasalar2@unl.edu \\ Mauricio Casares \\ University of Nebraska - Lincoln, mcasare1@bigred.unl.edu \\ Jacob Schmitz \\ University of Nebraska - Lincoln \\ See next page for additional authors
}

Follow this and additional works at: https://digitalcommons.unl.edu/civilengfacpub

Part of the Civil Engineering Commons

Sharma, Anuj; Bullock, Darcy M.; Velipasalar, Senem; Casares, Mauricio; Schmitz, Jacob; and Burnett, Nathaniel P., "Improving Safety and Mobility at High-Speed Intersections with Innovations in Sensor Technology" (2011). Civil Engineering Faculty Publications. 40.

https://digitalcommons.unl.edu/civilengfacpub/40

This Article is brought to you for free and open access by the Civil Engineering at DigitalCommons@University of Nebraska - Lincoln. It has been accepted for inclusion in Civil Engineering Faculty Publications by an authorized administrator of DigitalCommons@University of Nebraska - Lincoln. 


\section{Authors}

Anuj Sharma, Darcy M. Bullock, Senem Velipasalar, Mauricio Casares, Jacob Schmitz, and Nathaniel P. Burnett 
Published in Transportation Research Record (2011) no. 2259: 253-263. Copyright 2011, Transportation Research Board of the National Academies. DOI: 10.3141/225924. Used by permission.

\title{
Improving Safety and Mobility at High-Speed Intersections with Innovations in Sensor Technology
}

\author{
Anuj Sharma, Darcy M. Bullock, Senem Velipasalar, Mauricio Casares, Jacob Schmitz, and Nathaniel Burnett
}

\section{Abstract}

A series of innovations has been made in the vehicle sensors field. Technologies such as IntelliDrive and radar-based smart sensors make it possible to track each vehicle in proximity to an intersection. However, current technologies have limitations, such as lack of robustness, accuracy, or level of penetration. This paper assumes an accurate wide-area detector (WAD), which might be soon available, and highlights the potential benefits that might be derived in safety and efficiency of operations at high-speed intersections from the deployment of the WAD. Two critical areas in which wide-area detection can lead to significant improvements are discussed: (a) location of crash risk on onset of yellow and (b) location of vehicles on onset of yellow. A case study was conducted at an instrumented intersection in Noblesville, Indiana, to estimate potential improvement from the use of an ideally operating WAD and green extension logic for signal control. Findings revealed that the replacement of the single loop detector sensor with a WAD sensor would lead to an additional 1.4 vehicles being served per lane on the cross street per unit vehicle provided with dilemma zone protection on the high speed approach. Results also showed that speed traps should be used only after accounting for the trade-off between safety and efficiency and the traffic control logic. When speed traps were designed with generic dilemma zone boundaries at the Noblesville site, the dilemma zone protection was provided only $57 \%$ of the time because vehicles accelerated or decelerated after passing the speed trap.

The total number of vehicles in the dilemma zone has been used as a surrogate measure for safety at rural high-speed intersections. The dilemma zone was initially defined as the area in which the driver can neither stop comfortably nor clear safely on the onset of yellow. This approach uses detenninistic design values such as perception reaction time, comfortable deceleration rate, and length of yellow interval to determine the location of the dilemma zone $(1,2)$. The stopping and clearing distance for a vehicle are calculated. Stopping distance (Xs) is a distance from the stop bar before which any vehicle can stop with a comfortable deceleration. Clearing distance $(\mathrm{Xc})$ is a distance from stop bar after which any vehicle can cross the stop line with comfortable acceleration. The yellow phase is designed such as to eliminate the existence of the dilemma zone.

There are three possible scenarios based on the values of stopping distance and clearing distance:

Sharma (corresponding author, asharma3@unl.edu), Velipasalar, Casares, Schmitz, and Burnett, University of Nebraska-Lincoln, Lincoln, Nebraska, USA. Bullock, Purdue University, West Lafayette, Indiana, USA.
- Xs $>\mathrm{Xc}$. There is a dilemma zone $(\mathrm{Xs}>\mathrm{X}>\mathrm{Xc}$ ) in which a driver can neither stop comfortably nor clear safely.

- $\mathrm{Xs}=\mathrm{Xc}$. There is no dilemma zone.

- Xs $<$ Xc. There is an option zone or decision dilemma zone (Xs $<\mathrm{X}<\mathrm{Xc}$ ) in which a driver can stop comfortably as well as proceed safely.

The main limitation of this approach is that it assumes a perfect knowledge of all variables. In reality, drivers have a perception of various variables such as distance from the stop bar and yellow duration but lack perfect knowledge.

Researchers recharacterized the surrogate measure as the decision dilemma zone to take into account the variability in human perception (3). The decision dilemma zone is defined as that approach area within which the probability of deciding to stop on the display of yellow is within the range of $10 \%$ to $90 \%$. This zone is considered to have a higher risk for rear-end collisions and red light violations because the driver is not sure whether to proceed through the intersection or to attempt to stop. Throughout this paper the term "dilemma zone" will be used to describe this occurrence.

There have been several attempts to ascertain the dilemma zone boundaries (4-9). Initially, a frequency-based approach was used to obtain the probability of stopping. The percentage of drivers stopping for a given distance and speed was used to develop the cumulative distribution function. Researchers observed a significant variation in the dilemma zone boundaries obtained from frequency-based methods.

Binary discrete choice models were subsequently proposed to determine the probability of stopping for a given distance and speed for a better understanding of the underlying human decision models and explain the variation in the observed dilemma zone boundaries $(3,8,10-12)$. Throughout the paper this dilemma zone definition will be used. Speed and vehicle types have been the only two parameters that have been accounted for in establishing the dilemma zone boundaries even in the most advanced signal control logic. The dilemma zone boundaries have been reported to be affected by age distribution of the population, types of drivers (aggressive, nonaggressive), location of signal head, and so on $(11,12)$. Thus there is the need for measuring site-specific dilemma zone boundaries instead of the use of generic dilemma zone boundaries (for a given speed and vehicle type) for control at a high-speed intersection. In this paper, the teon "generic dilemma zone boundaries" is used to describe the current practice in which speed and vehicle type are the only two parameters assumed to be affecting dilemma zone boundaries. The site-specific dilemma zone boundaries are developed by an ideal wide area detector. These boundaries will not only account for the speed 
and vehicle type but also take into account any other factor affecting the dilemma zone boundaries. The sitespecific dilemma zone boundaries will be obtained in the field by automatic generation of the probability-of-stopping curves for each intersection.

There are two traffic control logic constructs that are being used at high-speed intersections: (a) green extension systems and (b) green termination systems. These constructs use different sensor types for detecting the number of vehicles in their dilemma zone.

Green extension systems are the most commonly implemented control algorithm at high-speed intersections in the United States. The objective of this control mechanism is to improve the safety at the intersection by allowing the driver in the dilemma zone to proceed safely through before the phase transition. The advance detectors present on the high-speed arterial mark the beginning of the dilemma zone. So the green through phase for northbound and southbound movements is extended until there is no vehicle present in the dilemma zone on either of the two approaches. Such a termination of the phase is called a "gap-out." The through phase can also be terminated if the traffic controller is unable to find a gap before the maximum green time has expired. Such a termination of the green phase is called a "maxout."

The efficiency and safety of green extension logic deteriorates when point detectors are used for sensing the presence or absence of vehicles in their dilemma zone. The reason is that the point detectors can report only the position of a vehicle at a specific point in space and time but not the speed of the vehicle. A relatively safe but inefficient approach is often followed for implementing green extension logic with just one point detector (13). This method uses the 85 th and 15 th percentile velocities from a historical distribution to determine a fixed location for the point detector near the start of the expected danger zone, as well as a fixed time for green extension after the detection of the presence of a vehicle at the fixed location. There are two drawbacks to this approach: (a) the set of generic dilemma zone boundaries used mayor may not be coincident with site-specific dilemma zone boundaries and (b) instances of overextension and dilemma zone incursions will occur as a result of extrapolation of vehicle track and wider area of protection provided because of missing speed information.

Researchers have used multiple point detector schemes, such as the Beirele method, Winston-Salem method (14), Southern Section Institute of Transportation Engineers (15), and Nebraska Department of Roads detector spacing (9), to improve the safety and efficiency of operations.

Unlike the green-extension systems described previously, green termination systems use a look-ahead window to determine the best time to end a phase. Examples of green termination systems are the intelligent detection-control system from Texas (16) and selfoptimizing signal from Sweden (17). These systems try to identify an appropriate time to end the green phase by predicting the value of a performance function for the near future. This performance function is based on the number of vehicles present in the dilemma zone and the opposing queue. The cost of safety is calculated by using the number of vehicles in their dilemma zone.
These control systems are not widely used because of the high technology cost. Green termination algorithms use speed traps to estimate vehicle speed and use probabilistic models to track the vehicle over time. Even these techniques do not measure sitespecific dilemma zone boundaries and are susceptible to incorrect markings for risk of crash. Also, when speed traps are used the acceleration and deceleration of a vehicle beyond the speed trap cannot be accounted for. Bleyl shows that the average speed and variance change as the vehicle approaches the stop bar during green (18). The effect of a traffic signal is different on different drivers. The effect is more pronounced as drivers move closer to the intersection.

Today, technologies such as IntelliDrive and radar-based smart sensor make it possible to track each individual vehicle in proximity to an intersection. The current technologies have their limitations, including robustness, accuracy, or level of penetration. This paper assumes an accurate wide-area detector (WAD), which might be available in the near future, and highlights the potential benefits that can be derived in safety and efficiency of operations at a high-speed intersection. A WAD can be of benefit in two critical areas: (a) it can automatically generate the site-specific dilemma zone boundaries and (b) it can detect any changes in speed (acceleration or deceleration) over a range of distance. This paper evaluates the potential benefits of using a WAD with green extension systems.

\section{Location of Crash Risk on Onset of Yellow}

The total number of vehicles in the dilemma zone is used as the surrogate measure for safety at high-speed intersections. Figure 1 plots the common threshold for dilemma zone boundaries as determined by several researchers $(3,4,6-9,19)$. These thresholds are compared against site-specific dilemma zone boundaries for a car traveling at $45 \mathrm{mph}$ at the highspeed intersection of SR-37 and SR-32 in Noblesville, Indiana (19). As can be seen from Figure 1, there is a high variation (on the order of $100 \mathrm{ft}$ ) in regard to the start and end of a dilemma zone for a given speed. This variation can be attributed to several factors such as behavioral characteristics of drivers, geometric characteristics of the intersection, rural or urban setting, and weather conditions.

Using a set of boundaries not obtained from the site of the intersection can lead to unsafe and inefficient operations. For example, if the dilemma zone boundaries (for a 45-mph car) of Bonneson et al. were to be used at this intersection, the region between Point a and Point c (shown in Figure 1) would have been protected instead of the region between band $\mathrm{d}$, which marks the site-specific dilemma zone boundaries (9). This finding implies that the region between Points a and b would be left unprotected leading to deteriorated safety and the region between Points c and $\mathrm{d}$ would be provided with unnecessary protection leading to inefficient operation of the intersection. So a set of generic dilemma zone boundaries can lead to unsafe and inefficient performance of the intersection, which can lead to an increased number ofcrashes on the main street and higher delays on the cross street. 


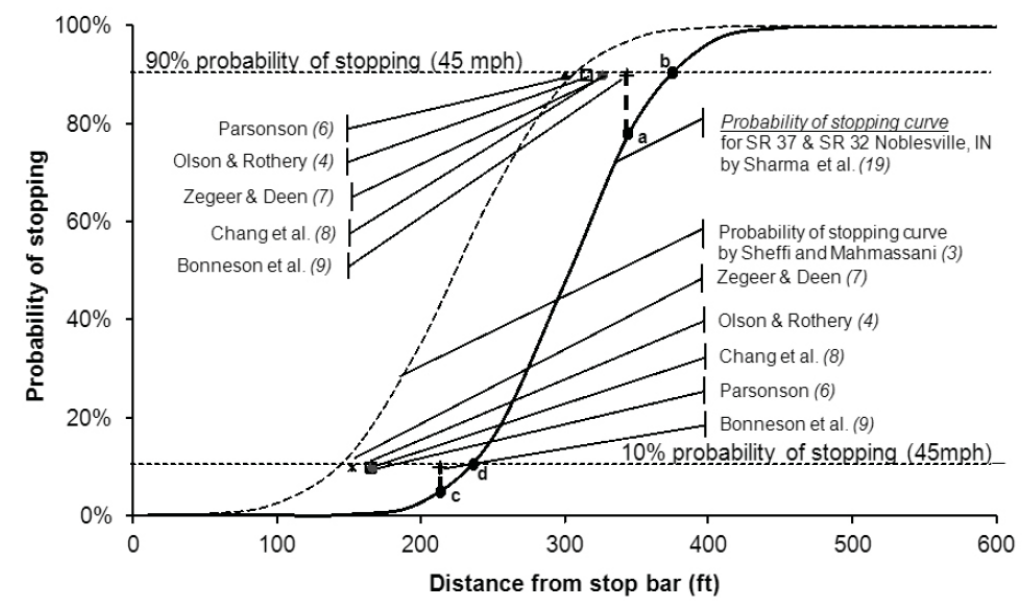

Figure 1 Site-specific dilemma zone boundary for car traveling at $45 \mathrm{mph}$.

A WAD can track individual vehicles and their stop and go decisions at the intersection. If the WAD is also provided with the signal phase indication information, the probability-of-stopping curve can be generated in real time and thus overcomes shortcomings present in all existing systems that use generic dilemma zone boundaries. Other improved surrogate measures of crash risk, such as probability of traffic conflict, can also be generated in real time by using the vehicle tracks provided by WAD (20).

\section{Location of Vehicles on Onset of Yellow}

The existing traffic control algorithms use the number of vehicles present in the dilemma zone to make the decision of termination or extension of green on the high-speed approach. Different sensor technologies are deployed to determine the number of vehicles present in a dilemma zone at a specific time. Figure 2 shows three existing technologies used to determine the number of vehicles in a dilemma zone. Figure $2 \mathrm{a}$ shows a single point detector that reports the presence or absence of a vehicle at a given distance at a particular time. Point detection has a significant limitation in dilemma zone protection because the dilemma zone protection boundaries vary with the speed of the vehicle as shown in Figure $3 \mathrm{~b}$. To provide dilemma zone protection, the speed and distance of a vehicle needs to be continuously observed beginning at the dilemma zone start boundary to the point at which the vehicle is at the end of the dilemma zone. Point detectors can give only the position of a vehicle at a single point in space and time. A conservative approach is thus used for providing dilemma zone protection with only one point detector. If the distribution of speeds at a specific high-speed intersection is known (as shown in Figure 3a), 85\% and 15\% speeds are used to determine the protected region. Figure $3 \mathrm{~b}$ graphically shows a typical implementation of dilemma zone protection with one point detector per approach. Typically, the zone of perceived danger is marked by using the upper boundary of the 85 th percentile velocity and a lower boundary of the 15 th percentile velocity. Vehicle extension time is calculated by using the total length of the zone of perceived danger and dividing it by the 15 th percentile ve- locity. A point detector is placed at the start of the perceived danger zone, and the phase is extended by a specific vehicle extension time for each detected vehicle. Figure $3 \mathrm{c}$ shows that a point detector extends a call for a vehicle traveling at $35 \mathrm{mph}$ for time $t_{3} \mathrm{~s}$, but the vehicle is in its dilemma zone for only $t_{1} \mathrm{~s}$ as shown in Figure $3 \mathrm{~d}$. The above described conservative approach lowers the efficiency of operations and results in higher delays for cross-street traffic. Hence, the use of a single point detector introduces an in-built inefficiency in the signal operation.

Figure $2 \mathrm{~b}$ shows a speed trap that consists of two point detectors. In addition to the presence or absence information, the speed trap also provides instantaneous speed information. The speed information is used to predict the vehicle track and determine the time during which the vehicle occupies its dilemma zone. This sensor technology addresses the limitation of in-built inefficiency in the case of a single point detector by using speed-sensitive dilemma zone boundaries for each vehicle, but this approach cannot account for random accelerations and deceleration occurring beyond the location of the speed trap. Thus an accelerating vehicle would clear its dilemma zone in a smaller time than predicted, but the green would be extended for the predicted time, leading to an inefficient operation, whereas a decelerating vehicle would still be occupying its dilemma zone beyond the predicted time, leading to an unsafe operation. Figure $2 \mathrm{c}$ shows an existing WAD. The WAD can significantly benefit dilemma zone protection algorithms by detecting the actual position and speed of every vehicle in the dilemma zone instead of using extrapolated values. The existing WAD has some limitations including inability to detect lanes, missed calls, and false calls described elsewhere (21).

This paper quantifies the potential benefits of an ideally operating WAD. The ideal WAD can significantly improve the performance at a high-speed intersection by generating site-specific dilemma zone boundaries and tracking each individual vehicle through the dilemma zone. A case study was conducted at the high-speed intersection at SR37 and SR-32 in Noblesville to quantify these benefits. At the conclusion, an evaluation of an existing wide area sensor technology is provided and suggestions for improvement of the WAD are discussed. 


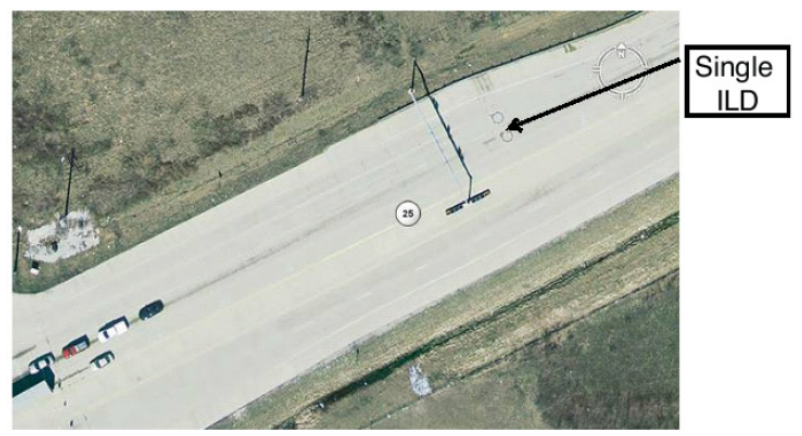

(a)

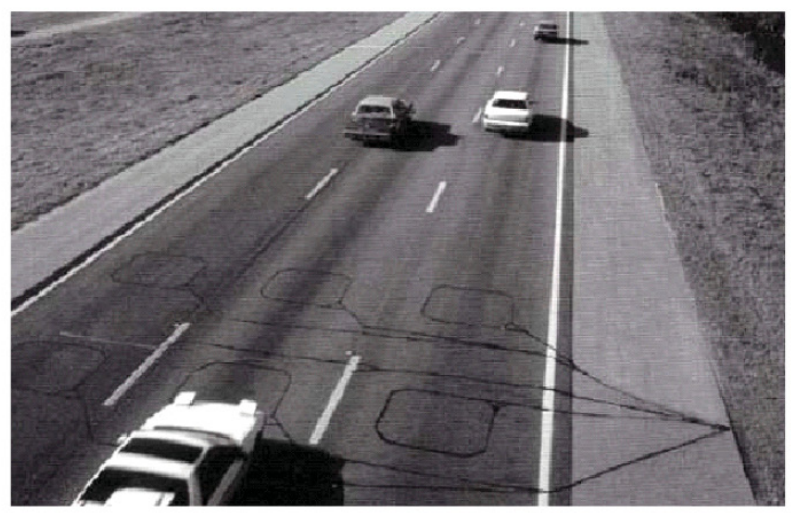

(b)

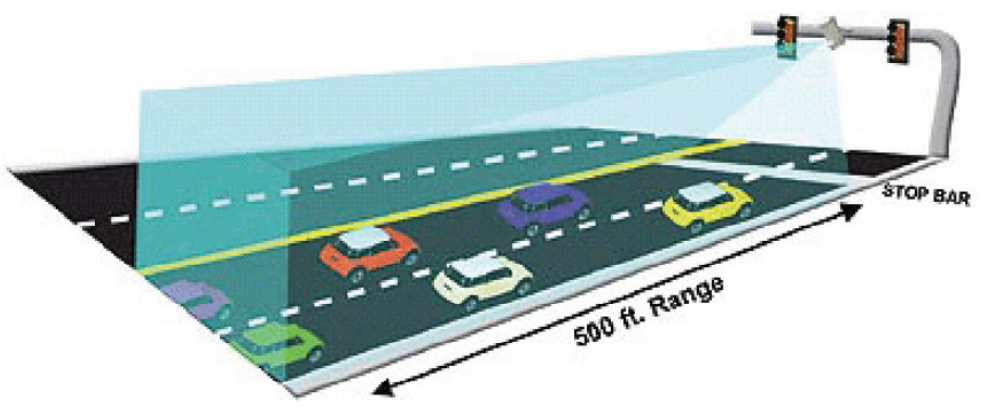

(c)

Figure 2 Existing sensor technologies being used for dliemma zone protection at high-speed intersection: (a) single inductive loop detector (ILD), (b) speed trap, and (c) wide area detector. (Source: http://www.wavetronix.com/products/smartsensor/200.)

\section{Site Description}

The data collection site is located at the signalized intersection of SR-37 and SR-32 in Noblesville as shown in Figure 4a. This instrumented intersection logs detector actuations, signal states, and simultaneous video recording of the existing traffic conditions. Figure $4 \mathrm{~b}$ shows the data collection environment used for performing the evaluation.

The detectors (Figure 4a) that were used for data collection included the following:

- NA7, NB7. Advanced point detectors are located $420 \mathrm{ft}$ away from the stop bar.
- NB WAD. The northbound WAD is located on the street light pole adjacent to the stop bar. The height of the sensor is $37 \mathrm{ft}$.

- NB camera. The video feed from the NB camera located on the signal mast arms was also fed to the PC for visual validation.

The detector actuations and phase change data were recorded in a data file. These data have a resolution of $1 / 1,000 \mathrm{~s}$ and are accurate to within approximately $1 / 100 \mathrm{~s}$. Video feeds with hypertext showing changes in the detector status and the signal phases were brought into the Pc. Real-time output from the WAD showing the ID, range, and distance for all detected vehicles was also brought into the Pc. Both fields were simultaneously recorded with screen capture software as shown in Figure 4b. This video was used for manual data reductions. 


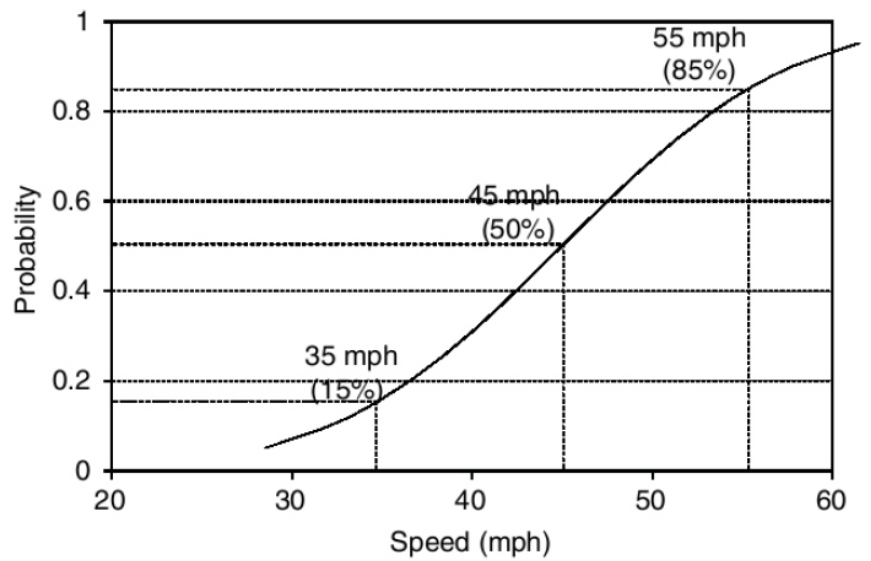

(a)

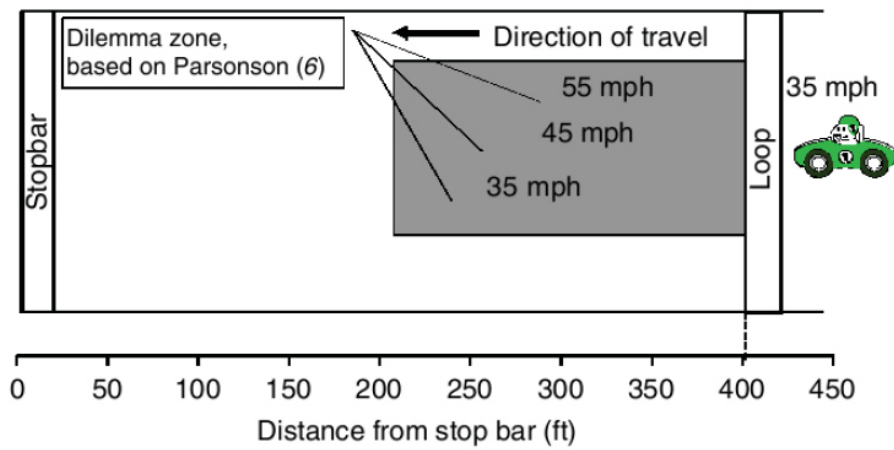

(b)

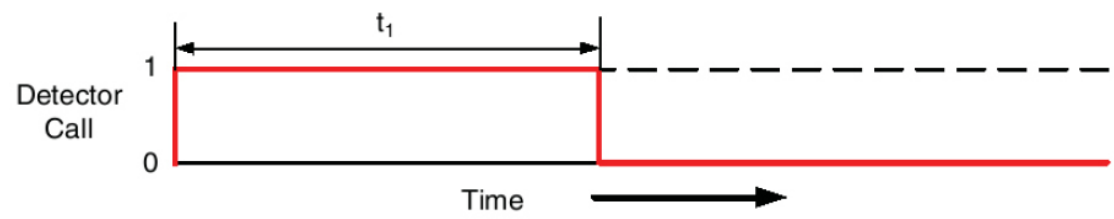

(c)

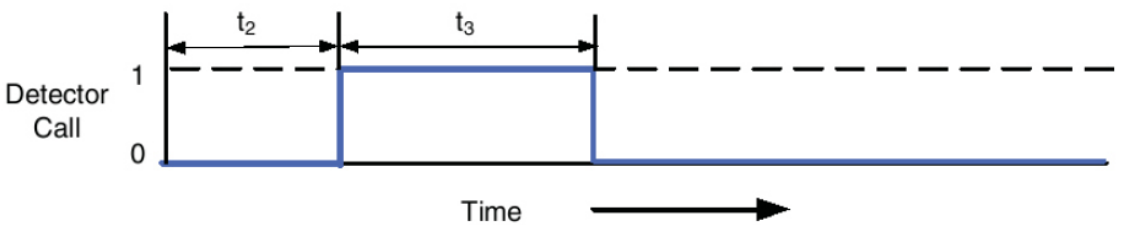

(d)

Figure 3 Typical implementation of green extension system with point detector and speed trap: (a) assumed speed distribution for hypothetical site, (b) implementation of gap-out logic with single loop and point speed detection, (c) call extension by single loop, and (d) call extension by speed trap.

Outputs from the NB WAD (ID, range, and speed) were also recorded as a text file. The speed of the vehicle obtained from the WAD detector was used as a substitute of speed obtained if a speed trap was present.

\section{Methodology}

This paper compares the performance of an ideal WAD with the use of site-specific dilemma zone boundaries (denoted by $\mathrm{WAD}_{\mathrm{s}}$ ) for pro viding dilemma zone protection against (a) single point detector (denoted by $\mathrm{L}_{\mathrm{G}}$ ), (b) speed trap (denoted by $\mathrm{S}_{\mathrm{G}}$ ), and (c) ideal WAD using generic dilemma zone boundaries (denoted by $\mathrm{WAD}_{\mathrm{G}}$ ). Ideal WAD will be able to track the exact location and speed of a vehicle in the vicinity of a high-speed intersection. For this study the data were manually reduced by watching side-by-side video and WAD data collected from the field. One hundred and ten vehicle tracks were identified as free-flowing vehicles on the high-speed intersection during the green time in the absence of any queues. The generic dilemma zone boundaries used for this study are $5.5 \mathrm{~s}$ to $3 \mathrm{~s}$ as suggested by Bonneson et al. (9). The site-specific dilemma zone boundaries determined by Sharma et al. were used for generating the ideal case sce- 


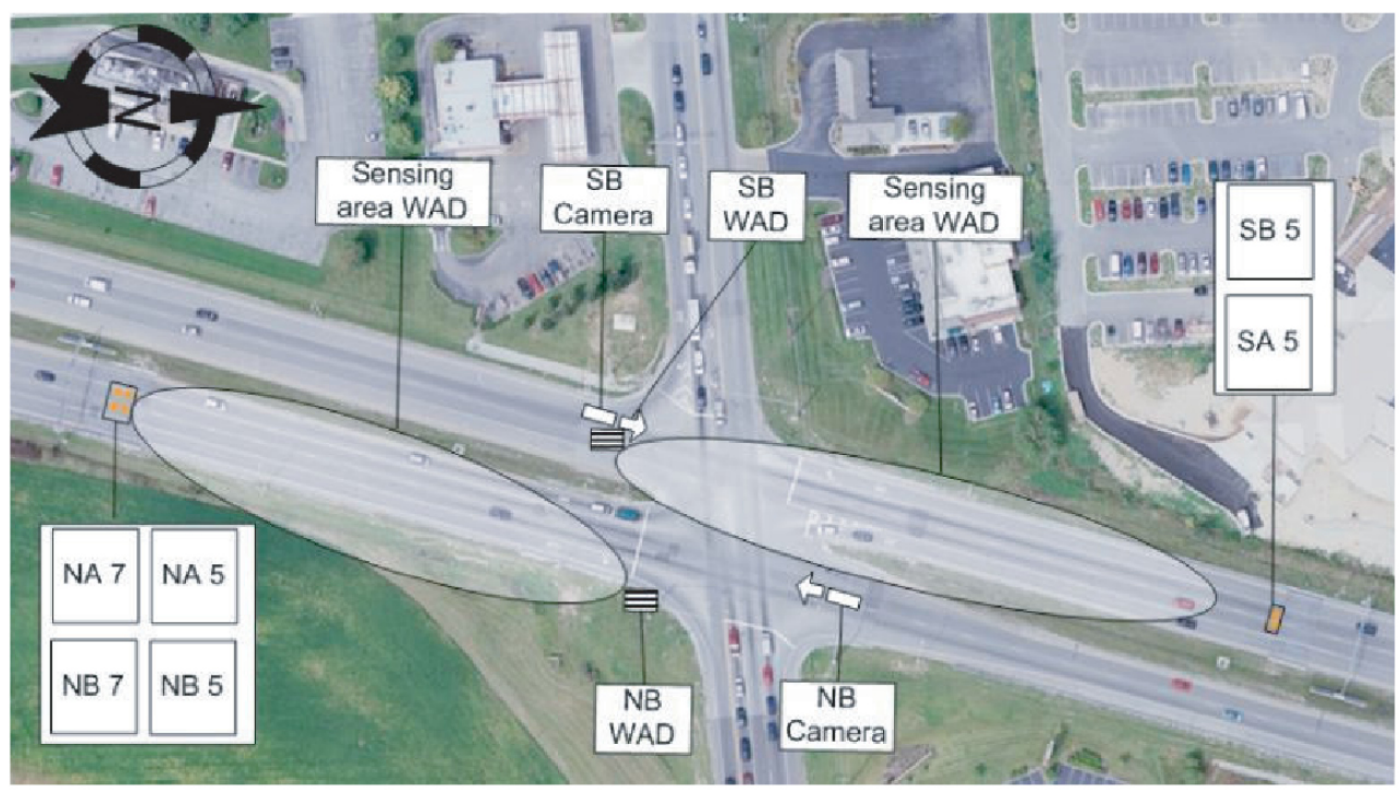

(a)

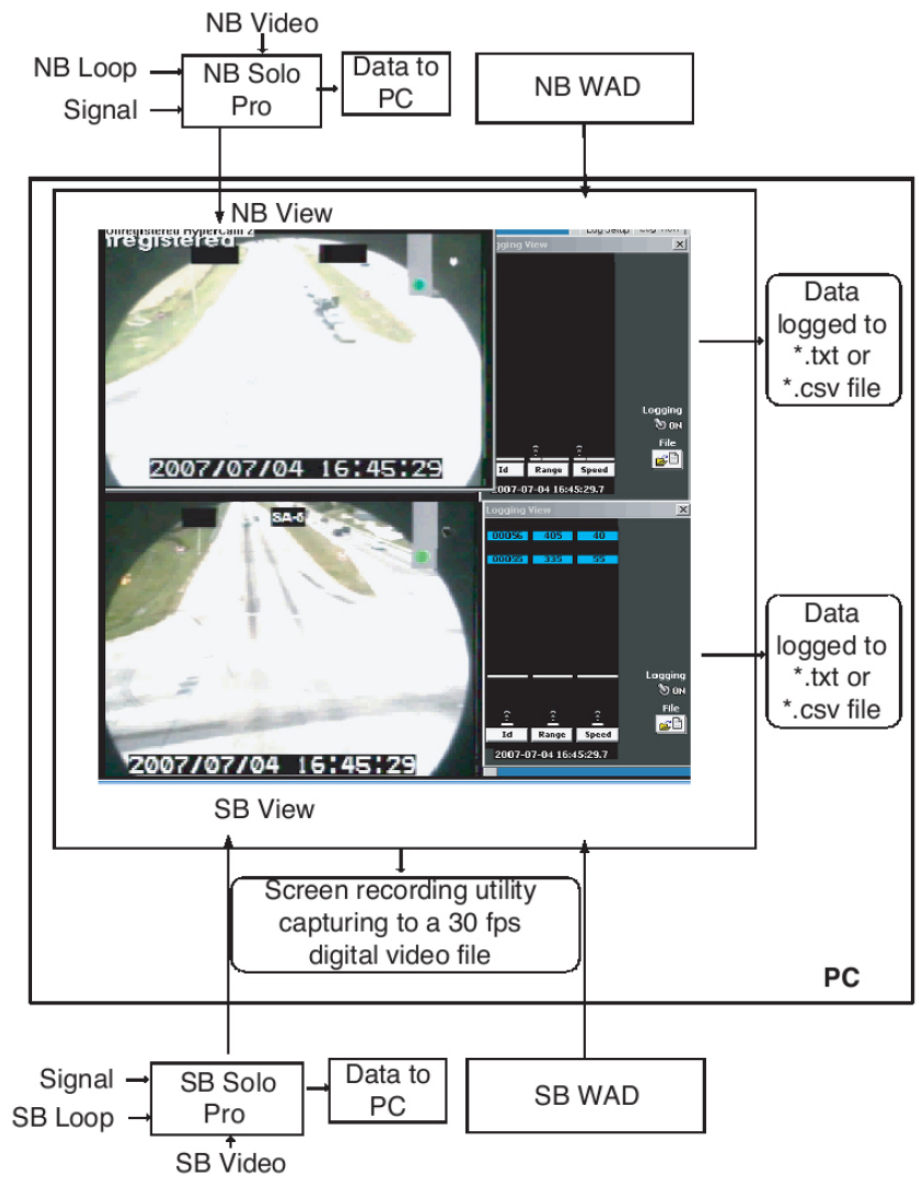

(b)

Figure 4 Data collection at SR-37 and SR-32 in Noblesville: (a) intersection layout INA = leftmost through lane in northbound (NS) direction, SA = leftmost through lane in southbound (581 direction) and (b) data collection environment. 


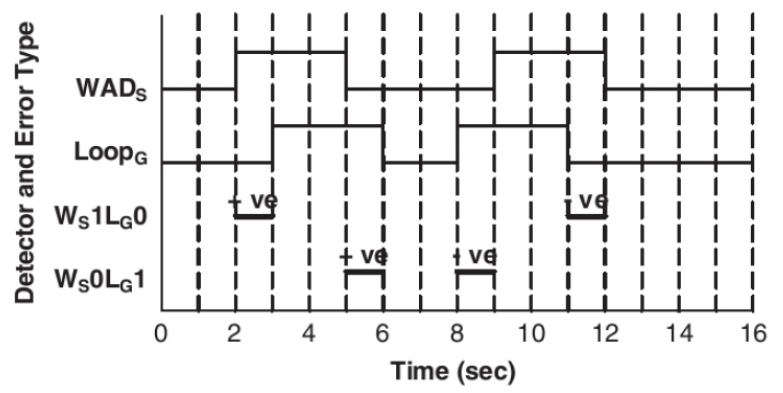

Figure 5 Discrepancy concept used for technology comparison.

nario (19). WAD $\mathrm{S}$ was assumed to exactly determine the duration of time a vehicle was in its site-specific dilemma zone. The extension times produced by $\mathrm{WAD}_{\mathrm{S}}$ were then compared against the extensions provided by the single loop, speed trap, and $\mathrm{WAD}_{\mathrm{G}}$ technology assuming they were using generic dilemma zone boundaries for extensions (to replicate the current practice).

Two types of discrepancies were observed when the extension provided by the $\mathrm{WAD}_{\mathrm{S}}$ was compared against the phase extension provided by a single loop, speed trap, or a $\mathrm{WAD}_{\mathrm{G}}$. Figure 5 shows a conceptual layout to illustrate the concept of discrepancy. In this figure, initially the loop detector and the $\mathrm{WAD}_{\mathrm{S}}$ detect no vehicle present in the dilemma zone. At time $t=2.0 \mathrm{~s}$, the $\mathrm{WAD}_{\mathrm{S}}$ detected one vehicle in its dilemma zone, but the loop did not register any call. Therefore, a discrepancy was identified in which the $\mathrm{WAD}_{\mathrm{S}}$ indicates one dilemma zone incursion while the loop does not indicate any presence. This discrepancy was labeled as $\mathrm{W}_{\mathrm{S}} 1 \mathrm{~L}_{\mathrm{G}} \mathrm{O}(+\mathrm{ve})$. The start point of the $\mathrm{WAD}_{\mathrm{S}}$ was used as the reference to measure the duration of the discrepancy. The loop activated after the WAD, indicating a positive sign. Similarly, between time $t=5.0$ sand $t=$ $6.0 \mathrm{~s}$, a discrepancy (duration $1 \mathrm{~s}$ ) occurs in which the $\mathrm{WAD}_{\mathrm{s}}$ extends the call for a vehicle until time $t=5.0 \mathrm{~s}$, but the loop extends the call until time $t=6 \mathrm{~s}$. This type of event was categorized as $\mathrm{W}_{\mathrm{s}} 0 \mathrm{~L}_{\mathrm{G}} 1$ (+ve). A similar concept was used in identifying discrepancies $\mathrm{W}_{\mathrm{S}} 1 \mathrm{~L}_{\mathrm{G}} \mathrm{O}(-\mathrm{ve})$ and $\mathrm{W}_{\mathrm{S}} 0 \mathrm{~L}_{\mathrm{G}} 1$ (-ve). With the above nomenclature, the discrepancies in the extensions of a speed trap were named $\mathrm{W}_{\mathrm{S}} 1 \mathrm{~S}_{\mathrm{G}} 0(+\mathrm{ve}), \mathrm{W}_{\mathrm{S}} 1 \mathrm{~S}_{\mathrm{G}} 0(-\mathrm{ve}), \mathrm{W}_{\mathrm{S}} 0 \mathrm{~S}_{\mathrm{G}} 1(+\mathrm{ve})$, and $\mathrm{W}_{\mathrm{S}} 0 \mathrm{~S}_{\mathrm{G}} 1(-\mathrm{ve})$, and for $\mathrm{WAD}_{\mathrm{G}}$ were named $\mathrm{W}_{\mathrm{S}} 1 \mathrm{~W}_{\mathrm{G}} 0(+\mathrm{ve}), \mathrm{W}_{\mathrm{S}} 1 \mathrm{~W}_{\mathrm{G}} \mathrm{O}(-\mathrm{ve}), \mathrm{W}_{\mathrm{S}} 0 \mathrm{~W}_{\mathrm{G}} 1$ (+ve), and $\mathrm{W}_{\mathrm{S}} 0 \mathrm{~W}_{\mathrm{G}} 1$ (-ve).

The nomenclature, in Figure 5, follows a simple syntax. The "w" designates a WAD and "L" or "s" designates a loop or a speed trap, respectively. The subscript "s" designates that site.specific dilemma zone boundaries were used, and subscript " $G$ " designates that generic dilemma zone boundaries were used. The number following each letter indicates whether the identified detector is extending the phase because of the presence of a vehicle in its dilemma zone (1) or the call is removed (0). The sign (+ve or -ve) represents whether the occurrence of the state change of the $\mathrm{WAD}_{\mathrm{S}}$ was before or after the state change of the other detector. Tables 1 through 3 explain the possible causes for each of the discrepancies and their effects on traffic operation for a loop detector, a speed trap, and a $\mathrm{WAD}_{\mathrm{G}}$, respectively. The consequences of detector discrepancies at a signalized intersection can affect safety and efficiency. A dropped call when a vehicle is still in its dilemma zone can lead to safety deterioration; extending the phase after a vehicle has cleared its dilemma zone can lead to inefficient operation and higher delays and also can cause max-outs. The difference in site-specific and generic dilemma zone boundaries affects all sensor technologies that do not use field data to define the dilemma zone boundaries.

The major cause of discrepancy in a loop detector is lack of information about the speed of the vehicle, which results in a conservative approach for dilemma zone protection, leading to poor efficiency.

The discrepancies in speed trap deployment occur mainly as a result of accelerating and decelerating traffic. The speed of the vehi cle changes after it crosses the speed trap, leading to a change in the true dilemma zone boundaries. For example, if a speed trap registers a vehicle traveling at $52 \mathrm{mph}$, the dilemma zone boundaries used by the protection logic will be 400 to $230 \mathrm{ft}$. But if the vehicle is decelerating and the speed drops to $40 \mathrm{mph}$, the lower threshold of the dilemma zone boundary would now be $176 \mathrm{ft}$. In this case, the protection provided with the speed trap would be removed earlier than the actual dilemma zone boundaries. A discrepancy of type W1SO (-ve) would be observed.

Comparison between $\mathrm{WAD}_{\mathrm{S}}$ and $\mathrm{WAD}_{\mathrm{G}}$ captures the effect of a shift in site-specific dilemma zone and generic dilemma zone.

Results

One hour of data was collected at the intersection in Noblesville. The free-flowing vehicles arriving at the green phase after the clearance of the initial queue were manually identified. One hundred and ten vehicles were identified as free-flowing vehicles during this peri-

Table 1 Common Causes of Observed Discrepancy in Loop Detector

\begin{tabular}{|c|c|c|c|c|}
\hline State & WAD Status & Loop Status & Comment & Impact \\
\hline $\mathrm{W}_{\mathrm{S}} 1 \mathrm{~L}_{\mathrm{G}} 0(+\mathrm{ve})$ & On & Off & $\begin{array}{l}\text { Loop detector turns on after } \mathrm{WAD}_{\mathrm{s}} \text { turns on. } \\
\text { Faster vehicle having dilemma zone upstream ofphysical location of loop }\end{array}$ & Safety \\
\hline $\mathrm{W}_{\mathrm{s}} 1 \mathrm{~L}_{\mathrm{G}} 0(-\mathrm{ve})$ & On & Off & $\begin{array}{l}\text { Loop detector turns off before WAD turns off. } \\
\text { Slower vehicle having dilemma zone downstream of dilemma zone boundary } \\
\text { used for loop }\end{array}$ & Safety \\
\hline $\mathrm{W}_{\mathrm{S}} \mathrm{OL}_{\mathrm{G}} 1(+\mathrm{ve})$ & Off & On & $\begin{array}{l}\text { Loop detector turns off after WAD turns off. } \\
\text { Faster vehicle leaving dilemma zone before loop gap-out }\end{array}$ & Efficiency \\
\hline $\mathrm{W}_{\mathrm{s}} 0 \mathrm{~L}_{\mathrm{G}} 1(-\mathrm{ve})$ & Off & On & $\begin{array}{l}\text { Loop detector turns on before WAD turns on. } \\
\text { Slower vehicle entering dilemma zone after loop registers the call }\end{array}$ & Efficiency \\
\hline
\end{tabular}


Table 2 Common Causes of Observed Discrepancy in Speed Trap

\begin{tabular}{|c|c|c|c|c|}
\hline State & WAD Status & $\begin{array}{l}\text { Speed Trap } \\
\text { Status }\end{array}$ & Comment & Impact \\
\hline $\mathrm{W}_{\mathrm{S}} 1 \mathrm{~S}_{\mathrm{G}} 0(+\mathrm{ve})$ & On & Off & $\begin{array}{l}\text { Faster vehicle having dilemma zone upstream of physical location of loop } \\
\text { Accelerating vehicle resulting in inaccurate prediction of dilemma zone boundaries } \\
\text { (upward shift) by speed at speed trap }\end{array}$ & Safety \\
\hline $\mathrm{W}_{\mathrm{s}} 1 \mathrm{~S}_{\mathrm{G}} 0(-\mathrm{ve})$ & On & Off & $\begin{array}{l}\text { Decelerating vehicles resulting in inaccurate prediction of dilemma zone boundaries } \\
\text { (downward shift) by speed at speed trap }\end{array}$ & Safety \\
\hline $\mathrm{W}_{\mathrm{s}} \mathrm{OS}_{\mathrm{G}} 1(+\mathrm{ve})$ & Off & On & $\begin{array}{l}\text { Accelerating vehicles resulting in inaccurate prediction of dilemma zone boundaries } \\
\text { (upward shift) by speed at speed trap }\end{array}$ & Efficiency \\
\hline $\mathrm{W}_{\mathrm{s}} 0 \mathrm{~S}_{\mathrm{G}} 1(-\mathrm{ve})$ & Off & On & $\begin{array}{l}\text { Decelerating vehicles resulting in inaccurate prediction of dilemma zone boundaries } \\
\text { (downward shift) by speed at speed trap }\end{array}$ & Efficiency \\
\hline
\end{tabular}

od. The single loop and speed trap (speed observed by WAD at 420 $\mathrm{ft}$ ) entries corresponding to these vehicles were also identified from the respective text files.

The data were then processed to calculate the duration of the phase extension for the identified vehicles by each of the three detectors using generic boundaries and by WAD using site-specific boundaries.

Discrepancies in the duration of the extension time were then calculated as described in Tables 1 through 3. Figure 6 shows the example tracks obtained for four vehicles with the use of four processes. The topmost plot $\left(\mathrm{WAD}_{\mathrm{S}}\right)$ in each track shows the ideal extension that should be provided if the information on the site-specific dilemma zone and vehicular track is known. The second, third, and fourth plots show whether $\mathrm{WAD}_{\mathrm{G}}$, loop, and speed trap, respectively, were used for providing protection over generic dilemma zone boundaries. From Figure 6, it can be seen that the single point detector (loop) extends the phase for the longest duration as expected and provides maximum inefficiency.

Table 4 shows the performance of each technology in relation to safety and efficiency respectively. As shown in Table 4, the loop detectors' performance in relation to safety is acceptable. The green starts after the vehicle has entered the dilemma zone in $14 \%$ of cases, and it ends earlier in $25 \%$ of cases. The vehicles on average are protected about $82 \%$ of the time when they are in their dilemma zones. The lower than expected performance in safety can be attributed to the fact that the site-specific dilemma zone boundaries are different from the generic dilemma zone boundaries.

Results in Table 4 show that the loop detector overextends at the start and the end of the extension at rates in the range of $75 \%$ to $85 \%$. The average overextension is also high on the order of $1.6 \mathrm{~s}$. The total overextension from 110 observed vehicles sums to 298.1 s. If provided to the cross street, these $298.1 \mathrm{~s}$ can result in the discharge of 149 vehicles per lane under an assumed saturation headway of $2 \mathrm{~s}$. That finding implies that an excess of approximately 1.36 vehicles per lane in the cross street can be served per unit vehicle protected for its dilemma zone.

The use of a speed trap improves the performance in regard to efficiency, but there is a stark drop in safety. The net overextension for the speed trap drops to $179.5 \mathrm{~s}$, which is a $40 \%$ drop in the overextension provided by the loop detector, but this comes at the cost of safety. The vehicles are protected only an average $57 \%$ of the time when they are in their true (site-specific) dilemma zone. There are two reasons for the drop in safety: (a) accelerating and decelerating vehicles are not protected for some duration and (b) generic dilemma zone boundaries are different from site-specific dilemma zone boundaries.

Finally, the comparison between $\mathrm{WAD}_{\mathrm{G}}$ and $\mathrm{WAD}_{\mathrm{S}}$ captures the effect of the shift in dilemma zone boundaries for Noblesville. A net of $45.4 \mathrm{~s}$ of overextension is caused by this shift. Also, $15 \%$ of the time, vehicles are not covered in their true dilemma zone if generic boundaries are used.

\section{Discussion of Existing WAD}

As observed from the previous section, using a WAD rather than extrapolated values can significantly benefit dilemma zone protection algorithms by detecting the actual position and speed of every vehicle in the dilemma zone. However, the WAD is still an emerging technology and provides noisy data. There is a range of $\mathrm{WAD}_{\mathrm{S}}$ in the field that promise to track a vehicle from a certain range of distance in advance of the stop bar. The performance requirements for the ideal operation of a WAD are as follows:

- Accurately detect vehicle entry. The WAD should be able to accurately detect all vehicles (with no false or missed detections) as they enter a certain location upstream of the stop bar. The required performance for the ideal operational range for a WAD depends on the dilemma zone boundaries for the given facility.

- Accurately track vehicle position. A WAD should precisely measure the position of each vehicle in the danger zone.

- Accurately track vehicle speed. A WAD should be able to precisely measure the speed of each vehicle in the danger zone.

Table 3 Common Causes of Observed Discrepancy in $\mathrm{WAD}_{\mathrm{G}}$

\begin{tabular}{lllll}
\hline State & $\begin{array}{l}\mathrm{WAD}_{\mathrm{S}} \\
\text { Status }\end{array}$ & $\begin{array}{l}\mathrm{WAD}_{\mathrm{G}} \\
\text { Status }\end{array}$ & $\begin{array}{l}\text { Comment on Site-Specific } \\
\text { Dilemma Zone Boundary }\end{array}$ & Impact \\
\hline $\mathrm{W}_{\mathrm{S}} 1 \mathrm{~W}_{\mathrm{G}} 0(+\mathrm{ve})$ & On & Off & Starts earlier than generic dilemma zone & Safety \\
$\mathrm{W}_{\mathrm{S}} 1 \mathrm{~W}_{\mathrm{G}} 0(-\mathrm{ve})$ & On & Off & Extends beyond generic dilemma zone & Safety \\
$\mathrm{W}_{\mathrm{S}} 0 \mathrm{~W}_{\mathrm{G}} 1(+\mathrm{ve})$ & Off & On & Ends earlier than generic dilemma zone & Efficiency \\
$\mathrm{W}_{\mathrm{S}} 0 \mathrm{~W}_{\mathrm{G}} 1(-\mathrm{ve})$ & Off & On & Starts later than generic dilemma zone & Efficiency \\
\hline
\end{tabular}




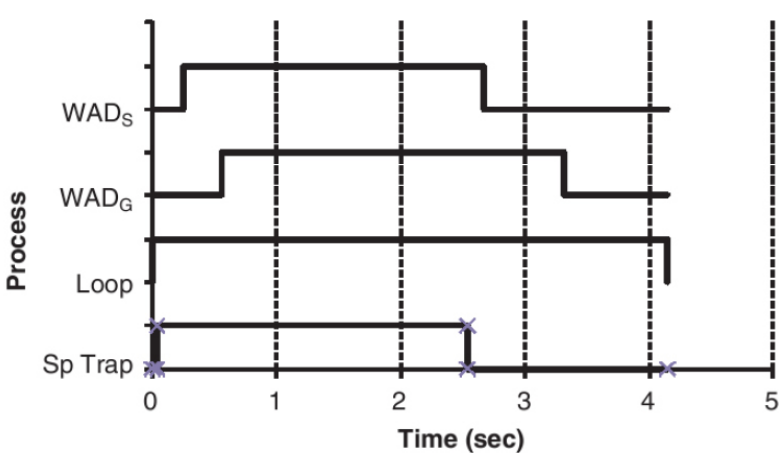

(a)

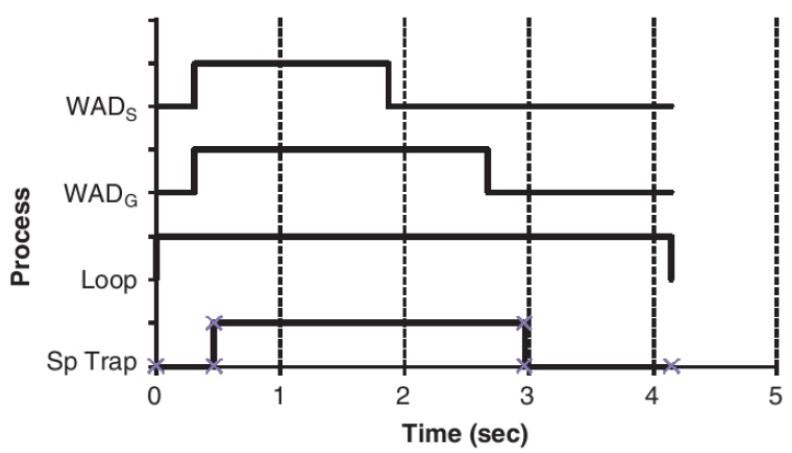

(c)

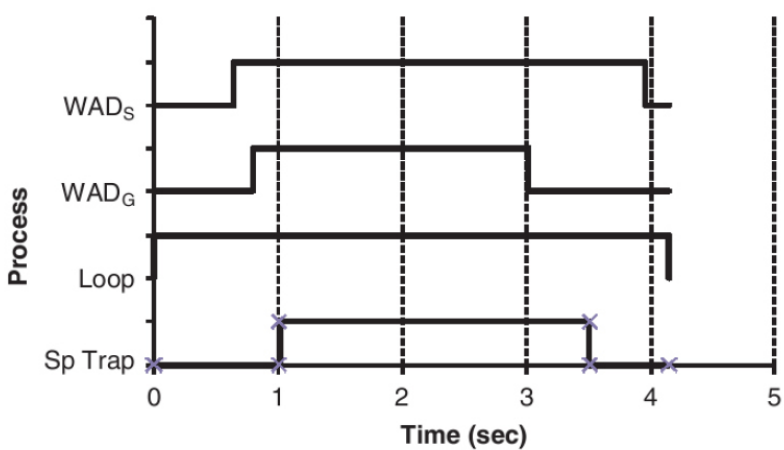

(b)

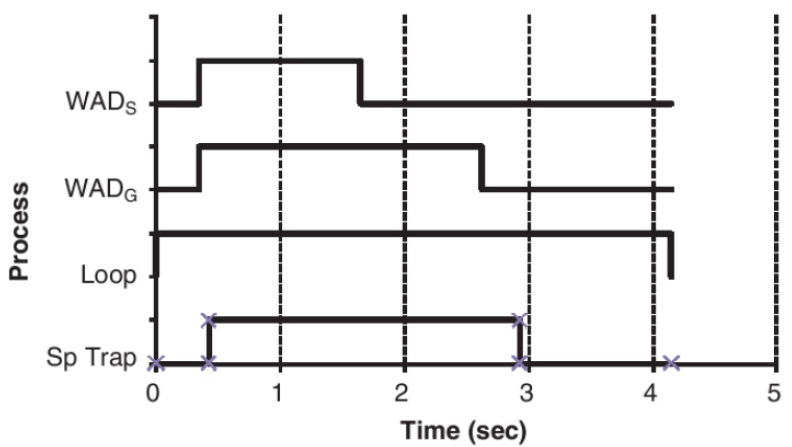

(d)

Figure 6 Example protection zone as provided by sensor types for four vehicle tracks ( $\mathrm{Sp}=\mathrm{speed})$.

- Accurately detect vehicle exit. A WAD should continuously sustain detection monitoring until a vehicle crosses a certain location in the vicinity of the stop bar.

For dilemma zone applications, the performance criteria are best evaluated during the green phase of the cycle after the initial queue has cleared. Performance of a radar-based technology (SmartSensor by Wavetronix) was evaluated according to the above performance measures at the intersection in Noblesville (21). However, a direct evaluation was not done on the operational performance of proprietary dilemma zone protection algorithms embedded in the SmartSensor (22). The performance of the metrics in the previously mentioned study are as follows:
- Accurately detect vehicle entry. The performance of the WAD for this metric was substandard as a result of the excessive number of false detections generated on tuming traffic and standing queues. Three to four occurrences of vehicles completely undetected by the WAD were also observed during an hour period.

- Accurately track vehicle position. Overall, the WAD perfonned well on this metric assuming that the correct vehicle was picked up and tracked.

- Accurately track the vehicle speed. The WAD performance was satisfactory for this metric. There were a few cases in which the

Table 4 Results of Comparison of Different Technology with WADs

\begin{tabular}{|c|c|c|c|c|c|c|}
\hline Characteristic & $\begin{array}{l}\text { Single Loop } \\
\text { Average (s) }\end{array}$ & Count $(\%)$ & $\begin{array}{l}\text { Speed Trap } \\
\text { Average (s) }\end{array}$ & Count $(\%)$ & $\begin{array}{l}\text { WAD }_{G} \\
\text { Average (s) }\end{array}$ & Count $(\%)$ \\
\hline \multicolumn{7}{|l|}{ Safety Comparison } \\
\hline Sensor extension starts after dilemma zone & 0.5 & 14 & 0.5 & 61 & 0.2 & 69 \\
\hline Sensor extension ends prior to dilemma zone & -1.8 & 25 & -1.3 & 29 & -1.4 & 13 \\
\hline Absolute total (s) & 45.9 & & 109.7 & & 39.2 & \\
\hline $\begin{array}{l}\% \text { of total dilemma zone time unprotected } \\
\text { Efficiency Comparison }\end{array}$ & 18 & & 43 & & 15 & \\
\hline Sensor extension starts prior to dilemma zone & -1.3 & 85 & -0.4 & 39 & 0 & 0 \\
\hline Sensor extension extends beyond dilemma zone & 1.6 & 75 & 1.0 & 71 & 0.47 & 76 \\
\hline Absolute total (s) & 298.1 & & 179.5 & & 45.4 & \\
\hline No. of vehicles (veh/lane) that can be served & 149 & & 90 & & 23 & \\
\hline
\end{tabular}


speed was not updated after a certain point in time. These errors were noticeable particularly when adjacent vehicles were moving closely together.

- Accurately detect vehicle exit. The performance of the WAD on this metric was seriously affected by the standing queues and turning volumes. The WAD needs to filter such noise from the data.

In summary, the WAD showed a considerable potential for improving the safety and efficiency of the dilemma zone protection algorithm. But the detection and tracking accuracy of the WAD need to be further improved, particularly when used on approaches with significant tuming traffic. The WAD also could not detect the lane of travel or vehicle type and hence cannot be used for vehicle-specific dilemma zone modeling. There have been some advances in the WAD and new radar-based products launched since this study; these new products need to be tested for their effectiveness for tracking and detection.

Work by the authors of this paper on sensor fusion technologies is also ongoing to further enhance the detection and tracking capabilities of WAD with the use of video-based vehicle tracking. Figure 7 shows an example of vehicle detection. The vehicle is identified with image processing, and a green box marking the extent of the vehicle is drawn. The centroid of this region shown by the small red box in Figure 7 can then be tracked to find the position and velocity of the vehicle over time. This information from radar-based and vision-based sensors can be fused to further improve the accuracy of tracking and detection. IntelliDrive-based products can also be used in combination with the above described sensor or individually according to the

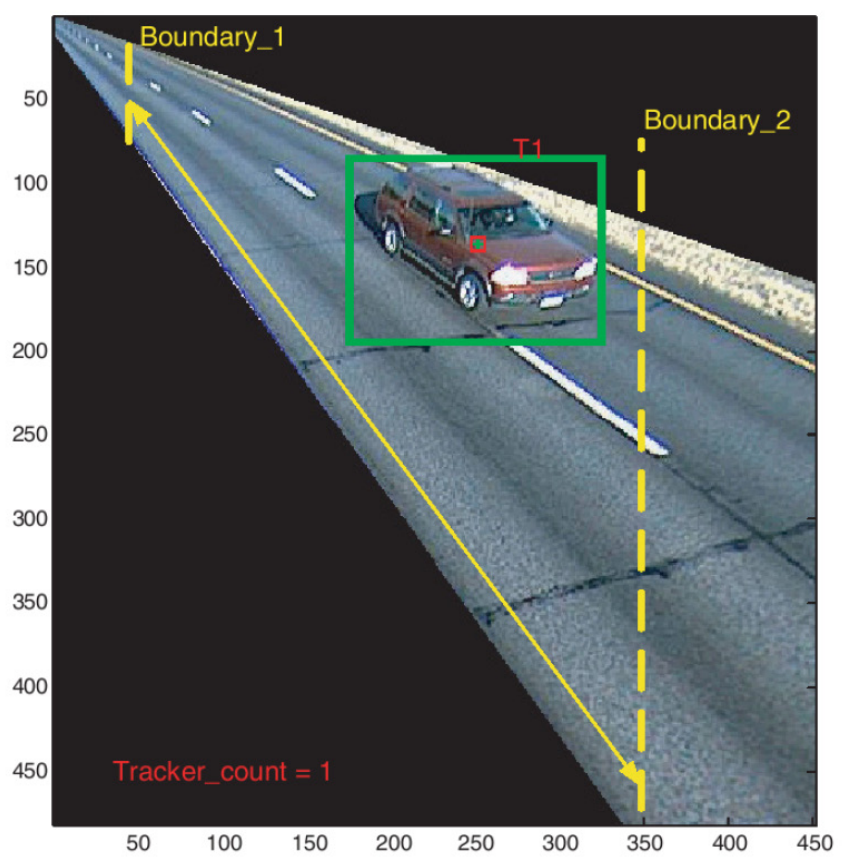

(a) level of penetration. If the WAD is being used for generating sitespecific dilemma zone boundaries, a fail-safe approach of using the threshold range for the dilemma zone boundaries should be used. If a sensor reports boundaries that are outside these thresholds, a flag will be raised requiring human intervention.

\section{Conclusions}

Results from this paper illustrate the potential benefits of an ideal wide area detector. The traffic engineer using an ideal WAD will not have to guess the dilemma zone boundaries. The sensor itself, when the phase and vehicle track information are used, will be able to develop the site-specific probability of stopping curves. The capability of tracking each individual vehicle in the vicinity of the intersection will eliminate the need for extrapolation of velocity or conservative dilemma zone boundaries. When providing dilemma zone protection, replacing the single loop detector sensor with a WAD sensor will lead to an additional 1.4 vehicles being served per lane on the cross street per unit vehicle provided with dilemma zone protection on the highspeed approach. The paper also shows that speed traps should be used only after taking into account the trade-off between safety and efficiency. For the Noblesville site, ifthe speed traps were designed by using generic dilemma zone boundaries, dilemma zone protection was provided only $57 \%$ of time. The results of the paper signify that automatic generation of site-specific dilemma zone boundaries and vehicle tracking provided by an ideal WAD can result in significant improvements in efficiency and safety at an intersection. The paper also discusses the existing WAD technologies. On the basis of existing technologies and ongoing research it can be ascertained that reliable WAD technologies will be available in the next few years.

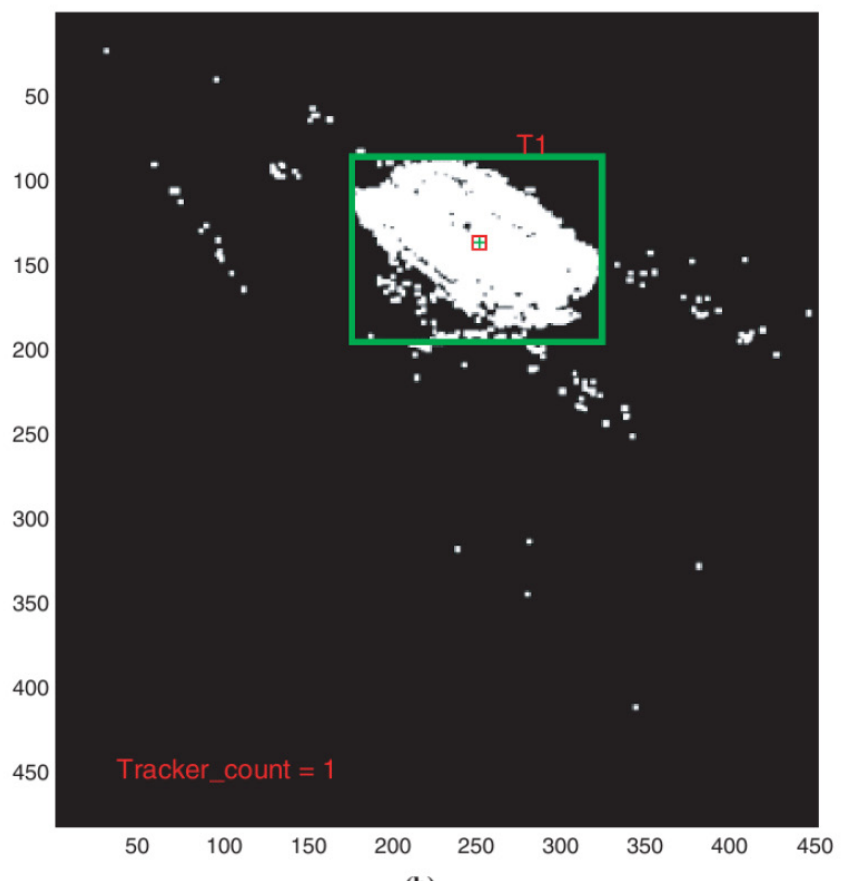

(b)

Figure 7. Example video-based vehicle tracking: (a) normal image and (b) image after background reduction. 
References

1. Gazis, D, R Hennan, and A Maradudin. The problem of the amber signal in traffic flow. Operations Research (1960) 8(1): 112-132.

2. May, AD. Clearance interval at traffic signals. Highway Research Record (1968) 221: 41-71. HRB, National Research Council, Washington, D.C.

3. Sheffi, Y, and H Mahmassani. A model of driver behavior at high speed signalized intersections. Transportation Science (1981) 15(1): 51-61.

4. Olson, PL, and R Rothery. Driver response to amber phase of traffic signals. Bulletin (1962) no. 330: 40-51. HRB, National Research Council, Washington, D.C.

5. Webster, FV, and PB Ellson. Traffic signals for high speed roads. RRL Technical Paper (1965) no. 74.

6. ITE Technical Committee 18 (P.S. Parsonson, chair). Small-area detection at intersection approaches. Traffic Engineering, Institute of Transportation Engineers, Washington, D.C. (1974): 8-17.

7. Zegeer, CV, and RC Deen. Green extension systems at high-speed intersections. ITE Journal (1978) 48(11): 19-24.

8. Chang, M-S, CJ Messer, and AJ Santiago. Timing traffic signal change intervals based on driver behavior. Transportation Research Record (1985) no. 1027: 20-30.

9. Bonneson, JA, PT McCoy, and BA Moen. Traffic detector design and evaluation guidelines. Report No. TRP-02-31-93 (1994). Nebraska Department of Roads, Lincoln, Nebraska.

10. Gates, TJ, DA Noyce, and L Laracuente. Analysis of driver behavior in dilemma zones at signalized intersections. Transportation Research Record (2007) no. 2030: 29-39.

11. Papaioannou, P. Driver Behavior, dilemma zone, and safety effects at urban signalized intersections in Greece. Accident Analysis and Prevention (2007) 39(1): 147-158. 12. Wonchul, K, J Zhang, A Fujiwara, TY Jang, and M Namgung. Analysis of stopping behavior at urban signalized intersections: empirical study in South Korea. Transportation Research Record (2008) no. 2080: 84-91.

13. Sharma, A, DM Bullock, and S Peeta. Limitations of simultane- ous gap-out logic. Transportation Research Record (2006) no. 1978: 42-48.

14. Sackman, H, PS Parsonson, B Monahan, and AF Trevino. Vehicle detector placement for high speed, isolated traffic-actuated intersection control. In: Manual of Theory and Practice, vol. 2. Report FHWA-RD-77-32 (1977). FHWA, U.S. Department of Transportation.

15. Parsonson, PS, RA Day, JA Gawlas, and GW Black, Jr. Use of ECDC detector for signalization of high-speed intersections. Transportation Research Record (1979) 737: 17-23.

16. Kronborg, P, F Davidsson, and J Edholm. SOS-Self-Optimising Signal Control development and field trials of the SOS algorithm for Self-Optimising Signal Control at isolated intersections. TFK Report (1997) 1997:2E. TFK-Transport Research Institute, Stockholm, Sweden.

17. Bonneson, J, D Middleton, K Zimmennan, H Charara, and M Abbas. Intelligent detection-control system for rural signalized intersections. Report no. FHWA/TX-03/4022-2 (2002). Texas Department of Transportation, Austin.

18. Bleyl, RL. Speed profiles approaching a traffic signal. Highway Research Record (1972) 384: 17-23.

19. Sharma, A, DM Bullock, and S Peeta. Estimating dilemma zone hazard function at high speed isolated intersection. Transportation Research, part C (2011) 19(3): 400-412.

20. Sharma, A, DM Bullock, and S Peeta. Recasting dilemma zone design as a marginal cost-benefit problem. Transportation Research Record (2007) no. 2035: 88-96.

21. Sharma, A, M Harding, B Giles, DM Bullock, J Sturdevant, and S Peeta. "Performance Requirement and Evaluation Procedures for Advance Wide Area Detector." Presented at 87th Annual Meeting of the Transportation Research Board, Washington, D.C., 2008.

22. Wavetronix. SmartSensor. Available at http://www.wavetronix. com/products/smart sensor/200. Accessed July 31, 2010.

The Traffic Signal Systems Committee peer-reviewed this paper. 